\title{
RESPONSABILIDAD SOCIAL CORPORATIVA: El compromiso de la Universidad con los ciudadanos
}

\section{Raquel PUENTES-POYATOS; África YEBRA-RODRÍGUEZ; Francisco GUERRERO}

Universidad de Jaén rpuentes@ujaen.es,ayebra@ujaen.es,fguerre@ujaen.es

\section{CORPORATE SOCIAL RESPONSIBILITY: The engagement of the university with citizenship}

El concepto de responsabilidad social corporativa (RSC) hace referencia al compromiso de los integrantes de una empresa o institución con la sociedad, sin olvidar la obligación tácitamente adquirida también entre ellos mismos. La RSC define por tanto la fundamental relación del conjunto empresarial (público o privado) con el medio ambiente y con los miembros potencialmente débiles de la sociedad en el más amplio sentido del concepto, en términos de justicia social, cooperación e igualdad.

En los últimos años son muchas las instituciones y empresas que incluyen la RSC entre sus objetivos. Por tanto, parece razonable que ésta aparezca como contenido transversal fundamental en los planes formativos de aquéllos que ocuparán los puestos de responsabilidad y toma de decisiones en el futuro más próximo. Y tanto más, cuanto mayor es el nivel académico de nuestros futuros emprendedores y profesionales. La Universidad de Jaén se adhirió en 2009 a los 10 principios del Pacto Mundial de Naciones Unidas, que se articulan en torno a la conservación del medio ambiente y el uso de tecnologías sostenibles, y a la protección de los derechos humanos fundamentales, incluyendo no sólo la no vulneración de los mismos sino el reconocimiento de derechos laborales y sociales adquiridos históricamente. Más allá de la RSC empresarial, nuestra universidad se mantiene firme en el compromiso de estar al servicio del entorno en el que se ubica, a través de su actividad docente, investigadora y de transferencia de conocimiento.

La Estrategia Universidad 2015 indica que la educación se ha convertido en una de las principales alternativas para afrontar la salida de la crisis económica occidental. Para construir un sistema productivo más sostenible, responsable y basado en el conocimiento es necesario introducir una nueva cultura que extienda valores comunes a todo el sistema, tales como el esfuerzo, el carácter emprendedor, la solidaridad, la ética y la cooperación. Tal y como se expone en la Comunicación de la Comisión al Consejo y al Parlamento Europeo relativa a la revisión de la estrategia para un desarrollo sostenible (2005):

"La educación desempeña un papel fundamental a la hora de favorecer los cambios necesarios en aras de un desarrollo sostenible. Garantiza la adquisición, por parte de los ciudadanos, de las competencias pertinentes para adaptarse a 
los cambios del mundo, la difusión de los conocimientos y la participación de las partes interesadas en el cambio", "La educación constituye una condición previa para fomentar cambios de comportamiento".

Así, la Estrategia Universidad 2015 propone una Universidad centrada en contenidos, actitudes y valores que forme ciudadanos profesionales, fomentando y desarrollando la formación en principios éticos y valores sociales y solidarios. Para ello se deben promover en la comunidad universitaria valores personales y ciudadanos socialmente responsables, que favorezcan un comportamiento ético, una conducta inclusiva de los otros y un compromiso objetivamente profesional, con acciones de sensibilización y formación para toda la comunidad universitaria.

Igualmente, en la Comunicación de la Comisión al Parlamento Europeo se menciona, con la intención de poner en práctica la asociación para el crecimiento y el empleo, y para hacer de Europa un polo de excelencia de la responsabilidad social de las empresas (2006), que:

\begin{abstract}
"Para que la RSE se convierta en una práctica empresarial corriente, deben desarrollarse entre los futuros empresarios, negociantes, gerentes y empleados los conocimientos y cualificaciones correctos. La RSE también es una cuestión de aprendizaje permanente. La Comisión solicita a las escuelas empresariales, las universidades y otros centros educativos que incorporen la RSE en la educación como competencia transversal".
\end{abstract}

Por lo tanto, se quiere impregnar a la educación de principios de responsabilidad social, fomentando la adquisición de competencias en principios éticos y valores sociales y solidarios, buscando de forma equilibrada la formación especializada y la formación humanista. Que los estudiantes adquieran competencias en responsabilidad social será fundamental para formar a los futuros profesionales (empleadores y empleados) con unos valores y actitudes éticas y morales, que los comprometan con el desarrollo sostenible, aspecto demandado por el mercado de trabajo y la sociedad actual. Igualmente se deberá fomentar la responsabilidad social en la vertiente docente, por la implicación que éstos tienen como transmisores de conocimientos y formadores de valores y competencias de ética y de responsabilidad.

Partiendo de estas premisas, el colectivo de profesores y profesionales que firman los manuscritos incluidos en este volumen especial decidieron aunar esfuerzos y conocimientos en distintas disciplinas para diseñar un curso sobre RSC que se ha impartido durante los cursos académicos 2014-15 y 2015-16 con el título "Introducción a la Responsabilidad Social", dirigido no sólo a alumnos y alumnas de la Universidad de Jaén, sino a cualquier miembro de la comunidad universitaria. Hemos pretendido introducir a los participantes en el curso en los principios que fundamentan la responsabilidad social, fomentando la adquisición de competencias en principios y valores éticos, sociales y medioambientales, que contribuyan a una excelencia especializada mediante una formación basada en la corresponsabilidad, solidaridad e interés por el bienestar colectivo, que nos comprometa a comportarnos como ciudadanos y profesionales socialmente responsables. El curso se ha desarrollado de forma no presencial, siguiendo una metodología e-learning, lo que permite adaptarse a las necesidades de los participantes. El objetivo ambicioso de este curso es la incorporación de los valores aprendidos a través de la RSC en la práctica personal (como ciudadanos) y profesional, para que se sea más consciente y responsable de las implicaciones de nuestras decisiones y actuaciones. Específicamente, los participantes en el curso deben: entender el concepto de responsabilidad social y su implicación a nivel organizacional, comprender los principios y dimensiones que integran la responsabilidad social, y conocer las principales áreas de la RSC: igualdad, sostenibilidad, consumo responsable, cooperación y voluntariado. 
Este volumen especial recoge parte del material docente preparado específicamente para este curso. El primer artículo presenta el concepto de RSC, sus principios rectores y principales prácticas, apoyado en un caso de estudio, la Universidad de Jaén. Finaliza con los instrumentos que cuentan las organizaciones para comunicar su RSC y sus beneficios.

El segundo artículo informa de la legislación nacional e internacional que fomenta la igualdad efectiva entre mujeres y hombres. Serán objeto de análisis las medidas de conciliación de la vida personal, familiar y laboral y la igualdad en la responsabilidad social de las empresas.

En el tercer artículo se analiza el concepto de ser humano en un planeta de recursos limitados, y se profundiza en la idea de medio ambiente con un enfoque holístico en una red interdependiente de sus tres dimensiones: biológica, social y económica. La incorporación de la sostenibilidad en todos los niveles (y en todas las dimensiones) de nuestra sociedad es una tarea complicada que a pasos muy pequeños comienza a implantarse a través de la información, la educación y el voluntariado ambiental.

En los artículos cuarto y quinto se estudia el concepto y características de los productos y servicios que se encuadran dentro de un consumo responsable y de un comercio justo. Son analizados tanto desde el punto de vista del consumidor como de las empresas, como productoras y como consumidoras de productos.

Este número especial finaliza con un manuscrito en el que se presentan cooperación y voluntariado como áreas de responsabilidad social que las empresas han de priorizar como acción social en la comunidad o comunidades más desfavorecidas. Además, se analizan las características del cooperante/voluntario como ciudadano y/o como persona vinculada a una empresa. Por último, el artículo introduce al lector en el voluntariado corporativo y la cooperación internacional. 